\title{
The use of 3-dimensional imaging of Holstein cows to estimate body weight and monitor the composition of body weight change throughout lactation
}

\author{
C. Xavier, ${ }^{1}$ Y. Le Cozler, ${ }^{1 *} \odot$ L. Depuille, ${ }^{2} \odot$ A. Caillot, ${ }^{2}$ A. Lebreton, ${ }^{2} \odot$ C. Allain, ${ }^{2}$ J. M. Delouard, ${ }^{3}$ L. Delattre, ${ }^{3} \odot$ \\ T. Luginbuhl, ${ }^{3} \odot$ P. Faverdin, ${ }^{1} \odot$ and A. Fischer ${ }^{2}$ \\ ${ }^{1}$ Physiologie, Environnement, Génétique pour l'Animal et les Systèmes d'Elevage (PEGASE), INRAE, Institut Agro, 35590, Saint Gilles, France \\ ${ }^{2}$ Institut de l'Elevage, 75595 Paris, France \\ ${ }^{3} 3 \mathrm{D}$ Ouest, 5 Rue de Broglie, 22300 Lannion, France
}

\section{ABSTRACT}

Three-dimensional (3D) imaging offers new possibilities in animal phenotyping. Here, we investigated how this technology can be used to study the morphological changes that occur in dairy cows over the course of a single lactation. First, we estimated the individual body weight (BW) of dairy cows using traits measured with 3D images. To improve the quality of prediction, we monitored body growth (via 3D imaging), gut fill (via individual dry matter intake), and body reserves (via body condition score) throughout lactation. A group of 16 Holstein cows - 8 in their first lactation, 4 in their second lactation, and 4 in their third or higher lactation - was scanned in 3D once a month for an entire lactation. Values of morphological traits (e.g., chest depth or hip width) increased continuously with parity, but cows in their first lactation experienced the largest increase during the monitoring period. Values of partial volume, estimated from point of shoulder to pin bone, predicted BW with an error of $25.4 \mathrm{~kg}$ $\left(\mathrm{R}^{2}=0.92\right)$, which was reduced to $14.3 \mathrm{~kg}$ when the individual effect of cows was added to the estimation model. The model was further improved by the addition of partial surface area (from point of shoulder to pin bone), hip width, chest depth, diagonal length, and heart girth, which increased the $\mathrm{R}^{2}$ of $\mathrm{BW}$ prediction to 0.94 and decreased root mean square error to 22.1 $\mathrm{kg}$. The different slopes for individual cows were partly explained by body condition score and morphological traits, indicating that they may have reflected differences in body density among animals. Changes in BW over the course of lactation were mostly due to changes in growth, which accounted for around two-thirds of BW gain regardless of parity. Body reserves and gut fill had smaller but still notable effects on body composition, with a higher gain in body reserves and gut fill for

Received September 24, 2021.

Accepted January 6, 2022.

*Corresponding author: yannick.lecozler@agrocampus-ouest.fr cows in their first lactation compared with multiparous cows. This work demonstrated the potential for rapid and low-cost 3D imaging to facilitate the monitoring of several traits of high interest in dairy livestock farming. Key words: 3-dimensional image, dairy cattle, body weight, body weight component

\section{INTRODUCTION}

Measurements of BW are commonly used to monitor morphological changes in dairy cattle during growth or lactation (Maltz, 1997) and are used to manage diet formulation, breeding, or health. However, change in BW is a cumulative variable that closely links together both short- and long-term changes. In the short term, BW change reflects differences in gut fill (Faverdin et al., 2017), whereas long-term changes reflect growth or the mobilization or accretion of body reserves (Banos et al., 2005; Friggens et al., 2011; Thorup et al., 2012). The BW can be measured with a weighing scale or estimated using equations based on morphological traits such as heart girth (HG; Heinrichs et al., 1992). However, these approaches are seldom used on commercial farms (Le Cozler et al., 2012) because they are time-consuming and require the manipulation and restraint of animals, which can be risky and stressful for both the operator and the animal. To overcome these issues, recent studies have demonstrated the potential of estimating BW using 3-dimensional (3D) imaging (Kuzuhara et al., 2015; Gomes et al., 2016; Song et al., 2018; Le Cozler et al., 2019b; Miller et al., 2019; Martins et al., 2020). This technology also provides access to traits that have seldom been measured (e.g., surface areas or volumes of living animals) or that have not yet been studied (diagonal length; DL), which could be of interest for livestock breeders (Le Cozler et al., 2019b).

We can also use 3D imaging to evaluate BCS (Fischer et al., 2015) or to estimate feed intake (Shelley et al., 2016). A change in BCS represents a change in body reserves; therefore, it is useful for the management of reproduction and nutrition (Roche et al., 2009). Both 
Table 1. The BCS, BW, milk production, and milk fat and protein percentages for the total herd of 65 cows and the studied group of 16 cows

\begin{tabular}{|c|c|c|c|c|c|c|c|c|}
\hline \multirow[b]{2}{*}{ Item } & \multicolumn{4}{|c|}{ Herd of 65 cows $^{1}$} & \multicolumn{4}{|c|}{ Group of 16 cows } \\
\hline & Mean & SD & Min & Max & Mean & $\mathrm{SD}$ & Min & $\operatorname{Max}$ \\
\hline $\mathrm{BCS}^{2}$ & 1.99 & 0 & 1.25 & 2.86 & 2.06 & 0.1 & 1.47 & 2.86 \\
\hline BW (kg) & 648.9 & 8.9 & 478.1 & 886.4 & 649.0 & 22.5 & 489.8 & 886.4 \\
\hline Milk production, $\mathrm{kg} / \mathrm{d}$ & 33.3 & 0.7 & 0.5 & 57.8 & 32.7 & 1.4 & 2.3 & 52.9 \\
\hline Fat, $\mathrm{g} / \mathrm{kg}$ & 39.2 & 0.5 & 18.2 & 78.9 & 38.3 & 0.9 & 18.2 & 66.3 \\
\hline
\end{tabular}

${ }^{1}$ Min = minimum; Max = maximum.

${ }^{2}$ BCS was recorded once a month based on the 0-to-5 scale developed by Bazin et al. (1984).

BW and BCS can be recorded on commercial farms. Instead, the quantification of individual feed intake, which is often used to estimate the weight of mealrelated gut fill (Chilliard et al., 1987; Rémond et al., 1995), is currently conducted only on research farms. However, with the advent of 3D technology (Shelley et al., 2016), data on changes in gut fill and body reserves might soon be widely available to commercial farms. Indeed, 3D imaging can be used to measure numerous traits that, taken together, give an overall picture of the changes in body composition over any timeframe of interest, from a single lactation to an entire lifetime. Here, we demonstrate the potential of this technique by using 3D imaging to monitor the growth of lactating dairy cows. Our objectives were to compare the growth of lactating cows of different parities and to estimate BW based on 3D morphological traits. The analysis of growth was performed in the following 2 ways: one based on commonly used morphological traits, and another based on the change in different components of BW (body reserves, gut fill, and growth).

\section{MATERIALS AND METHODS}

All procedures were approved by the local ethics committee and the French Ministry of Higher Education, Research, and Innovation (reference number APAFIS 3122-2015112718172611).

\section{Experimental Design}

The experiment was performed from October 2017 to June 2018 at the Mejusseaume experimental station of INRAE, Dairy Nutrition and Physiology unit [IE PL, 35560 Le Rheu, France (https://doi.org/10.15454/ yk9q-pf68) under agreement for animal housing no. C-35-275-23]. A total of 16 lactating Holstein cows, of which 8 were in their first lactation $(\mathbf{L 1}), 4$ in their second lactation (L2), and 4 in their third lactation or higher (L3), were monitored over the course of their lactations. All cows calved between September 5 and
October 10, 2017. For cows in their first lactation, age at first calving was $23 \mathrm{mo}$ ( $\pm 1 \mathrm{mo})$. During the experiment, average BW was $649 \mathrm{~kg}( \pm 89.9 \mathrm{~kg})$, and average milk yield was $32.3 \mathrm{~kg} / \mathrm{d}$ per cow $( \pm 5.5 \mathrm{~kg} / \mathrm{d}$ per cow; Table 1). All cows were members of a larger experimental group of 65 ; here, we chose to work with only a subset of 16 individuals to investigate the usefulness and relevance of this new technology. On average, the performance of these 16 cows was similar to that of the group as a whole (Table 1), so that they could be considered to be representative of the entire group. In selecting the cows for this study, we chose individuals that would represent as much variability as possible in BW and BCS.

Cows were housed in a cubicle barn with fresh straw bedding distributed daily. They were fed individually with a TMR. From the time of calving to March 18, 2018, the TMR contained $6.62 \mathrm{MJ}$ of net energy $/ \mathrm{kg}$ of $\mathrm{DM}$ and $104.9 \mathrm{~g}$ of $\mathrm{MP} / \mathrm{kg}$ of $\mathrm{DM}$; it comprised $65 \%$ corn silage, $18 \%$ soybean meal, $9 \%$ energy concentrates, and $8 \%$ dehydrated alfalfa (as \% of diet DM). From March 19 to the end of the experiment, the TMR contained $5.98 \mathrm{MJ}$ of net energy $/ \mathrm{kg}$ of $\mathrm{DM}$ and $92.9 \mathrm{~g}$ of $\mathrm{MP} / \mathrm{kg}$ of $\mathrm{DM}$, and was $59 \%$ corn silage, $13 \%$ soybean meal, $2 \%$ energy concentrates, $14 \%$ dehydrated alfalfa, and $12 \%$ straw (as \% of diet DM). Cows were fed ad libitum to allow a maximum of $10 \%$ refusal and had free access to fresh water. In this experimental barn, each cow has its own feed trough, which it could only access via an electronic identification collar. Daily feed intake was calculated for each individual as the difference between the daily feed allowance and refusals. Refusals were collected and weighed individually every day at $0700 \mathrm{~h}$; the composition of refusals was assumed to be similar to the composition of the overall feed allowance. The DM for silage was determined 5 times per week, whereas DM of the concentrates was determined once per week. Feed was sampled once per week to evaluate nutrients. Values of feed DM were then used to estimate the dry DMI for each feed for each cow, and added up to get the total DMI per cow and per day. 


\section{Data Collection}

After each milking (twice per day, at 0700 and at 1600 h), cows were individually and automatically weighed on a static weighing station (DeLaval France) located at the exit of the milking parlor. Only morning BW was kept (i.e., before the distribution of fresh TMR) because these values fluctuated less day to day than the evening weight. The BCS was recorded for each cow once per month based on the 0-to- 5 scale developed by Bazin et al. (1984); scoring was performed by 3 trained technicians, and the scores were averaged to obtain 1 BCS per cow per scoring session. In general, all dried or lactating cows at the facility were scored monthly by these 3 technicians, representing up to 180 animals per month. Every 20 cows, the technicians compared their scores; if the difference was less than 0.25 point, they continued scoring. If 2 scores for a given cow differed by more than 0.25 points, the technicians went back to the animal, discussed their notes, and scored it again until they achieved a similar score (difference of 0.25-point max). Because it was performed monthly, the individual score could be determined on d 0 to 30 of lactation.

Morphological traits were quantified from 3D images recorded once per month during lactation, the same day as BCS recording. The $3 \mathrm{D}$ images of the cows were acquired automatically using the Morpho3D device, which is a sliding acquisition system located near the weighing scale, described in detail in Le Cozler et al. (2019a). Briefly, 5 cameras paired with a laser projector were placed at equal distances over a sliding frame. The frame moved at a mean speed of $0.5 \mathrm{~m} / \mathrm{s}$ to scan the animal from back to front (phase 1) and returned to its initial position at a mean speed of $0.3 \mathrm{~m} / \mathrm{s}$ with the cameras deactivated (phase 2). Each camera generated its own cloud of points; these were then automatically merged into a single cloud of points that represented the entire cow. This single cloud of points was cleaned and smoothed with a screened Poisson surface-reconstruction algorithm to create a triangulated mesh (Kazhdan and Hoppe, 2013) using Metruxo software, developed by $3 \mathrm{D}$ Ouest. On each 3D image, measurements of hip width (HW), HG, chest depth (CD), withers height (WH), DL, partial volume, and partial surface area were extracted; these were recorded as morphological traits as described by Le Cozler et al. (2019a,b). At the beginning of the experiment, a few animals had to be restrained in a head locker for scanning because they were nervous. For those animals, only the area between the shoulders and the pin bones was available for analysis, and the volume and surface area extracted from those partial images were designated partial volume and partial surface. Although those 2 variables were incomplete, previous work has demonstrated they are close enough to total volume and total surface (see Le Cozler et al., 2019b) to be considered good indicators of the total.

\section{Data}

Outlier Management. For each cow, preliminary data were cleaned to obtain well-behaved and smooth output curves for DMI and BW that could be used for further analysis. Outlier correction was performed using methods based on locally estimated scatterplot smoothing (LOESS). For BW, outliers occurred when either the scale was not tared correctly or if the cow moved too much during weighing. For DMI, outliers were often linked to device malfunction. For each cow, each observation in the time series of DMI or BW was smoothed with a LOESS regression based on the $40 \%$ (for DMI) or $20 \%$ (for BW) of data points that were the closest in time to the value under consideration, using the LOESS function in R software (https://www.r -project.org/). A value was considered to be an outlier if it was outside 2 (BW) or 3 (DMI) standard deviations of the average value of the closest neighbors. Because BW had more day-to-day variation, these steps (from smoothing to outlier detection) were repeated until the new smoothed curve did not differ significantly from the previous smoothed curve. The removed outliers represented on average $2.0 \%$ and $1.8 \%$ of the total values for BW and DMI, respectively.

After outlier removal, the BW series of each cow was again smoothed with LOESS using the $15 \%$ of data that were closest in time to better reflect changes in maintenance and to be less sensitive to changes in daily gut fill. To derive daily BCS estimates, the monthly observations were smoothed using a cubic spline with the function smooth.spline in $\mathrm{R}$ software, using each scoring day as a knot.

Missing Values. A few 3D images were of poor quality due to the cow's position or poor lighting conditions and were removed from the data set (Le Cozler et al., 2019b). The missing measurements were estimated as the linear interpolation between the measurements of the previous and the following months. As explained above, the 3D scans from October to March (period 1) were performed using a head lock to prevent cows from moving when being scanned. From April to June (period 2), though, the cows were kept calm through the use of concentrates on the floor; this resulted in images in which cows had their heads down and in several other positions while eating. This variability in head position affected several morphological traits, espe- 
cially WH. The effect of this restraint strategy on $\mathrm{WH}$ was corrected with an ANOVA that included "period" as a variable, using the ANOVA function of the "car" package (Fox and Weisberg, 2011) in R software.

Statistical Analysis. Because the 3D variables were estimated only once per month, we used only the BCS, DMI, and BW data captured of the day of 3D recording. We compared BW, BCS, and our main traits of interest over the course of a single lactation using a mixed model that included month number as a fixed effect and cow identity as a random effect. To compare between lactations, we compared BW, BCS, and the main traits of interest at the start of each lactation, and then examined the changes in these variables from mo 1 to 9 . A linear model including the effect of parity number (L1, L2, or L3) was used for one-way ANOVA. For each comparison listed, pairwise comparison was carried out based on least squared means with the lsmeans function of package "lsmeans" (Lenth, 2016) in $\mathrm{R}$; only mean values are presented here.

Changes During Lactation. The objective here was to decompose the change in BW into its 3 components - change in growth, body reserves, and gut fillto check for differences among cows of different parity. To do this, we fitted a mixed model that included a random effect of cow applied to the intercept and all slopes, using the lme function of package "nlme" (Pinheiro et al., 2018) in R. The final model was the one with the smallest Akaike information criterion value, as shown below:

$$
\begin{gathered}
\left(\mathrm{BW}_{\mathrm{t}}-\mathrm{BW}_{\mathrm{Oct}}\right)=\mu+\mathrm{a} \times\left(\mathrm{DMI}_{\mathrm{t}}-\mathrm{DMI}_{\mathrm{Oct}}\right) \\
+\mathrm{b} \times\left(\mathrm{BCS}_{\mathrm{t}}-\mathrm{BCS}_{\mathrm{Oct}}\right)+\mathrm{c} \times\left(\mathrm{DL}_{\mathrm{t}}-\mathrm{DL}_{\mathrm{Oct}}\right)+\mathrm{d} \\
\times\left(\mathrm{CD}_{\mathrm{t}}-\mathrm{CD}_{\mathrm{Oct}}\right)+\mathrm{e} \times\left(\mathrm{WH}_{\mathrm{t}}-\mathrm{WH}_{\mathrm{Oct}}\right)+\mathrm{f} \\
\times\left(\mathrm{HW}_{\mathrm{t}}-\mathrm{HW}_{\mathrm{Oct}}\right)+\mathrm{g} \times\left(\mathrm{DL}_{\mathrm{t}}-\mathrm{DL}_{\mathrm{Oct}}\right)+\mathrm{h} \\
\times\left(\mathrm{HW}_{\mathrm{t}} \times \mathrm{WH}_{\mathrm{t}} \times \mathrm{DL}_{\mathrm{t}}-\mathrm{HW}_{\mathrm{Oct}}\right. \\
\left.\times \mathrm{WH}_{\mathrm{Oct}} \times \mathrm{DL}_{\mathrm{Oct}}\right)+\varepsilon
\end{gathered}
$$

where $\mu, \mathrm{a}, \mathrm{b}, \mathrm{c}, \mathrm{d}, \mathrm{e}, \mathrm{f}, \mathrm{g}$, and $\mathrm{h}$ are the regression parameters, $t$ is the experimental month, Oct is October, and $\varepsilon$ is the error. Based on this model, we decomposed the change in BW as follows:

"Gut fill change" was calculated as the difference between the smoothed DMI value of the day of the first $3 \mathrm{D}$ scan $\left(\mathrm{DMI}_{\mathrm{oct}}\right)$ and the smoothed DMI value of the day of the $3 \mathrm{D}$ scan in each subsequent month $\left(\mathrm{DMI}_{\mathrm{t}}\right)$ as follows:

$$
\text { Gut fill change }=\mathrm{a} \times\left(\mathrm{DMI}_{\mathrm{t}}-\mathrm{DMI}_{\mathrm{Oct}}\right) .
$$

"Body reserves change" (adipose tissue changes) was calculated as the difference between the smoothed $\mathrm{BCS}$ of the day of the first $3 \mathrm{D}$ scan $\left(\mathrm{BCS}_{\text {Oct }}\right)$ and the smoothed BCS of the day of the 3D scan in each subsequent month $\left(\mathrm{BCS}_{\mathrm{t}}\right)$ as follows:

$$
\text { Body reserves change }=\mathrm{b} \times\left(\mathrm{BCS}_{\mathrm{t}}-\mathrm{BCS}_{\mathrm{Oct}}\right) .[3]
$$

"Growth" (muscle and bone changes) was calculated as the difference between the monthly value of each morphological variables $\left(\right.$ Variable $_{t}$ ) and its value from the first month of experimentation ( Variable $_{\text {oct }}$ ), as follows:

$$
\begin{gathered}
\text { Growth change }=\mathrm{d} \times\left(\mathrm{CD}_{\mathrm{t}}-\mathrm{CD}_{\mathrm{Oct}}\right)+\mathrm{e} \\
\times\left(\mathrm{WH}_{\mathrm{t}}-\mathrm{WH}_{\mathrm{Oct}}\right)+\mathrm{f} \times\left(\mathrm{HW}_{\mathrm{t}}-\mathrm{HW}_{\mathrm{Oct}}\right)+\mathrm{g} \\
\times\left(\mathrm{DL}_{\mathrm{t}}-\mathrm{DL}_{\mathrm{Oct}}\right)+\mathrm{h} \times\left(\mathrm{HW}_{\mathrm{t}} \times \mathrm{WH}_{\mathrm{t}} \times \mathrm{DL}_{\mathrm{t}}\right. \\
\left.\quad-\mathrm{HW}_{\mathrm{Oct}} \times \mathrm{WH}_{\mathrm{Oct}} \times \mathrm{DL}_{\mathrm{Oct}}\right),
\end{gathered}
$$

where we included $\mathrm{CD}, \mathrm{WH}, \mathrm{HW}$, and DL, as well as the product of $\mathrm{HW} \times \mathrm{WH} \times \mathrm{DL}$ as an estimation of the volume, as indicators of growth.

To determine if there were differences in each of these 3 components between cows of different parities, we fitted a one-way ANOVA including the effect of lactation number and estimated the least squared means with the lsmeans function of package "lsmeans" (Lenth, 2016) in R for each of the 3 components.

Volume as a Predictor of $B W$. Previous results indicated that volume and surface area calculated from 3D images can be relevant predictors of BW (Le Cozler et al., 2019b). However, the predictions obtained in that earlier work suggested that the relationship between $3 \mathrm{D}$ predictors and $\mathrm{BW}$ varies among cows and perhaps throughout lactation. For this reason, we adapted our model to take such variation into account. To do so, we first predicted BW with partial volume only as follows:

$$
\mathrm{BW}=\mu+\mathrm{a} \times \mathrm{PV}+\varepsilon,
$$

where $\mu$ is the intercept, $a$ is the slope for partial volume, PV is the partial volume, and $\varepsilon$ is the error (Table 2 ). To improve this, we then added other $3 \mathrm{D}$ predictors to the model (Table 2 equation [6]) or added individual intercepts and slopes to equation [5] to account for potential individual differences. Finally, all variables, including the additional 3D predictors, were subjected to "backward" selection based on $P$-values, so that all variables in the final model had $P$-values smaller than or equal to 0.05 . Our second approach fitted a mixed 
Table 2. Equations for estimating BW based on 3-dimensional morphological traits using either a simple model or mixed model with a random effect of cows on the intercept $\left(\mu_{\mathrm{i}}\right)$ and slopes $\left(\text { coefficient } \mathrm{a}-\mathrm{c}_{\mathrm{i}}\right)^{1}$

\begin{tabular}{ll}
\hline $\begin{array}{l}\text { Equation } \\
\text { number }\end{array}$ & Equation \\
\hline$[5]$ & $\mathrm{BW}=\mu+\mathrm{a} \times \mathrm{PV}+\varepsilon$ \\
{$[6]$} & $\mathrm{BW}=\mu+\mathrm{a} \times \mathrm{PV}+\mathrm{b} \times \mathrm{PS}+\mathrm{c} \times \mathrm{HW}+\mathrm{d} \times \mathrm{CD}+\mathrm{e} \times \mathrm{DL}+\mathrm{f} \times \mathrm{HG}+\varepsilon$ \\
{$[7]$} & $\mathrm{BW}=\left(\mu+\mu_{\mathrm{i}}\right)+\left(\mathrm{a}+\mathrm{a}_{\mathrm{i}}\right) \times \mathrm{PV}+\varepsilon$ \\
{$[8]$} & $\mathrm{BW}=\left(\mu+\mu_{\mathrm{i}}\right)+\left(\mathrm{a}+\mathrm{a}_{\mathrm{i}}\right) \times \mathrm{PV}+\left(\mathrm{b}+\mathrm{b}_{\mathrm{i}}\right) \times \mathrm{HW}+\left(\mathrm{c}+\mathrm{c}_{\mathrm{i}}\right) \times \mathrm{HG}+\varepsilon$ \\
\hline${ }^{1} \mathrm{PV}=$ partial volume; $\mathrm{PS}=$ partial surface $\mathrm{HW}=$ hip width; $\mathrm{CD}=$ chest depth; $\mathrm{DL}=$ diagonal length; HG
\end{tabular}
$=$ heart girth.

model between BW and partial volume, and included a random effect of the cow on the slope and the intercept (Table 2, equation [7]) to individualize the model for each cow. Indeed, the observation of different slopes and intercepts among cows in equation [7] meant that all cows did not have the same relationship between change in partial volume and change in BW. The share of the variation in $\mathrm{BW}$ explained by each component was then calculated for each month and each cow as the product of the slope and the variable at hand. The best mixed model (smallest Akaike information criterion) predicted BW with partial volume, HW, and HG, and included a random effect of the cow on the intercept and on each slope (Table 2 equation [8]). Both approaches were then combined to see if this could improve the precision of the model.

Differences Among Individuals in Density Changes. Among different cows, a change of $1 \mathrm{~L}$ in partial volume did not necessarily represent the same amount of change in $\mathrm{BW}$; in other words, the cows would not all exhibit the same change in terms of kilograms per liter (i.e., body density). With this in mind, we tried to better understand the origin of the amongcow differences in body density change over the course of lactation. Therefore, we extracted the individual slopes and compared them with the average change in body density over the 9 mo of the experiment using a linear regression approach. The change in density was calculated each month as the difference between the density (BW/partial volume) of that month subtracted from the density in October. Those 9 values were then averaged per cow to obtain a single value for change in density for each cow. After verifying that the differences among slopes truly represented differences in body density change over the course of lactation, the next step was to explain this change in density over the lactation using our measured variables. Changes in body density may represent changes in body composition because different body tissues do not all have the same density; for example, body reserves differ in density from muscle tissues. Therefore, a linear regression was fitted to explain each monthly change in density using the associated monthly changes in BCS, DL, and CD (which appeared to best reflect morphological changes), as follows:

$$
\begin{array}{r}
\text { density }_{\mathrm{t}}-\text { density }_{\text {Oct }}=\mu+\mathrm{a} \times\left(\mathrm{BCS}_{\mathrm{t}}-\mathrm{BCS}_{\mathrm{Oct}}\right)+\mathrm{b} \\
\times\left(\mathrm{CD}_{\mathrm{t}}-\mathrm{CD}_{\mathrm{Oct}}\right)+\mathrm{c} \times\left(\mathrm{DL}_{\mathrm{t}}-\mathrm{DL}_{\mathrm{Oct}}\right)+\varepsilon, \quad[9]
\end{array}
$$

where $\mu, \mathrm{a}, \mathrm{b}$, and $\mathrm{c}$ are the regression parameters, and $\varepsilon$ is the error.

The variables that significantly $(P \leq 0.05)$ explained the differences among cows in body density change over time were added to equation [7] by directly replacing the random slopes in equation [7]. For example, in the case that changes in BCS, CD, and DL were all found to explain differences in body density change, then the new version of equation [7] would be as follows:

$$
\begin{aligned}
\mathrm{BW}=\mu+\mathrm{a} & \times \mathrm{PV}+\mathrm{b} \times \mathrm{PV} \times\left(\mathrm{BCS}_{\mathrm{t}}-\mathrm{BCS}_{\mathrm{Oct}}\right) \\
+\mathrm{c} \times \mathrm{PV} & \times\left(\mathrm{CD}_{\mathrm{t}}-\mathrm{CD}_{\mathrm{Oct}}\right)+\mathrm{d} \times \mathrm{PV} \\
& \times\left(\mathrm{DL}_{\mathrm{t}}-\mathrm{DL}_{\mathrm{Oct}}\right)+\varepsilon,
\end{aligned}
$$

where $\mu, \mathrm{a}, \mathrm{b}, \mathrm{c}$, and $\mathrm{d}$ are the regression parameters, and $\varepsilon$ is the error.

Other morphological traits (partial surface, HG, CD, DL) and BCS were then added as simple effects without interactions to see if that could improve the quality of the relationship, as follows:

$$
\begin{gathered}
\mathrm{BW}=\mu+\mathrm{a} \times \mathrm{PV}+\mathrm{b} \times \mathrm{PV} \times\left(\mathrm{BCS}_{\mathrm{t}}-\mathrm{BCS}_{\mathrm{Oct}}\right) \\
+\mathrm{c} \times \mathrm{PV} \times\left(\mathrm{CD}_{\mathrm{t}}-\mathrm{CD}_{\mathrm{Oct}}\right)+\mathrm{d} \times \mathrm{PV} \\
\times\left(\mathrm{DL}_{\mathrm{t}}-\mathrm{DL} \mathrm{Lct}_{\mathrm{Oct}}\right)+\mathrm{e} \times \text { partial surface }+\mathrm{f} \times \mathrm{HW} \\
+\mathrm{g} \times \mathrm{HG}+\mathrm{h} \times \mathrm{CD}+\mathrm{i} \times \mathrm{DL}+\mathrm{j} \times \mathrm{BCS}+\varepsilon,[11]
\end{gathered}
$$

where $\mu, a, b, c, d, e, f, g, h, i$, and $j$ are the regression parameters, $t$ is the experimental month, Oct is October, and $\varepsilon$ is the error.

Model Comparison. To evaluate the different models, the coefficient of determination $\left(\mathrm{R}^{2}\right)$ and root mean squared error (RMSE) were compared. For the simple model, $\mathrm{R}^{2}$ was the adjusted value calculated with the base function "summary" of $\mathrm{R}$ software. 


\section{RESULTS}

\section{Growth of Dairy Cows}

Linear measurements, circumference, and volume all increased with the number of lactations, indicating that cows were still growing after their first lactation (Figures 1, 2, and 3; Tables 3 and 4). A comparison of mean values at mo 1 of lactation revealed a significant increase from L1 to L3 in most parameters, with the exception of BCS. Hip width was significantly different between lactations, whereas DL, volume, and BW also tended to increase (albeit in a nonsignificant way, $P<$ 0.1 ). The highest gains in growth were observed in L1 cows. In this group, HW and CD increased by $0.03 \mathrm{~m}$ and $0.06 \mathrm{~m}$, respectively, compared with $0.02 \mathrm{~m}$ and $0.04 \mathrm{~m}$, respectively, in L2 and L3 cow groups. Likewise, L1 cows demonstrated a larger gain in HG than L2 and L3 counterparts as follows: $+0.21 \mathrm{~m}$ versus $+0.13 \mathrm{~m}(P$ $=0.08$; Table 4$)$. The BW increased by an average of $82 \pm 37 \mathrm{~kg}$ for all cows, with no significant difference between cows $[+91.2 \pm 14 \mathrm{~kg}$ and $+72.8 \pm 12 \mathrm{~kg}$ for $\mathrm{L} 1$ and $(\mathrm{L} 2+\mathrm{L} 3)$ cows respectively; $P=0.34]$. When we examined the changes in our selected morphological traits (Table 4), we found that all increased significantly and continuously during the first lactation except for



Figure 1. Body weight $(\mathrm{kg})$, partial surface area $\left(\mathrm{PS} ; \mathrm{dm}^{2}\right)$, and partial volume (PV; L) according to average age, presented by parity $(\mathrm{n}=8$ primiparous, 4 in their second lactation, and 4 in their third lactation or higher)
Lactation category $-1-2-3$

Traits $-\mathrm{DL}(\mathrm{m}) * \mathrm{HW}(\mathrm{m}) \Leftrightarrow \mathrm{WH}(\mathrm{m})$
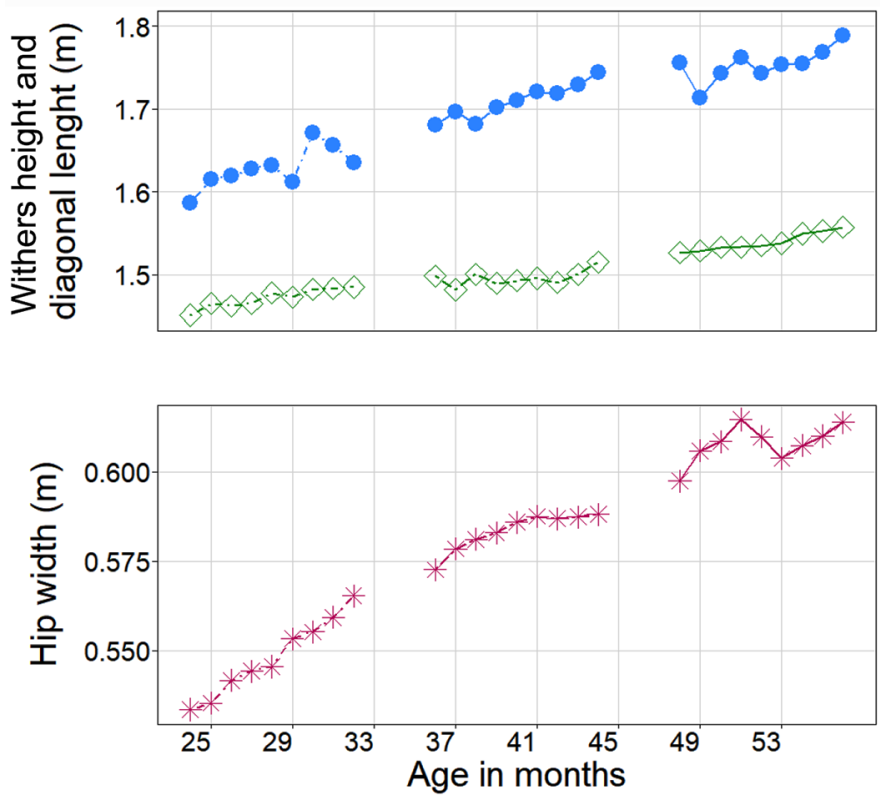

Figure 2. Withers height (WH; m), hip width (HW; m), and diagonal length (DL; $\mathrm{m}$ ) according to average age, presented by parity $(\mathrm{n}=8$ primiparous, 4 in their second lactation, and 4 in their third lactation or higher).

DL. Most traits continued to increase during L2 or L3, with the exception of surface area in $\mathrm{L} 2$, and $\mathrm{WH}$ and HG in L3 and higher.

The decomposition of BW into its 3 components (growth, body reserves, and gut fill) revealed different profiles among the 16 cows with respect to BW gain, regardless of BW at calving (Figure 4). The growth component was the most important contributor to BW gain in L1 cows, representing $62.0 \%$ of the change in BW over the course of lactation. Changes in gut fill and body reserves accounted for $24.6 \%$ and $9.0 \%$ of the total change, respectively, with the remainder corresponding to the residual error of the model (i.e., the variation that was not explained by the model). In multiparous cows, growth represented on average $69.1 \%$ of BW gain, whereas gut fill and body reserves accounted for an average of $4.4 \%$ and $18.3 \%$ of the gain, respectively (error of $4.8 \%$ ). In absolute terms, growth represented $56.5 \mathrm{~kg}$ and $50.3 \mathrm{~kg}$ of BW gain for L1 and (L2 + L3) cows, respectively (Table 5). Body reserves increased by $8.2 \mathrm{~kg}$ and $13.1 \mathrm{~kg}$ in L1 and (L2 + L3) cows, respectively, whereas gut fill tended to increase more in L1 cows than in (L2 + L3) cows $(+22.4 \mathrm{~kg}$ versus $+3.2 \mathrm{~kg}$, respectively; $P=0.09$, Table 5$)$. 
Table 3. Comparison of morphological trait values among lactations 1,2 , and 3 or higher (mean values for the first month of lactation)

\begin{tabular}{lccc}
\hline Item & Lactation 1 & Lactation 2 & Lactation 3 \\
\hline Partial volume, $\mathrm{m}^{3}$ & $563^{\mathrm{a}}$ & $645^{\mathrm{ab}}$ & $727^{\mathrm{b}}$ \\
Partial surface, $\mathrm{m}^{2}$ & $5.01^{\mathrm{a}}$ & $5.45^{\mathrm{ab}}$ & $5.79^{\mathrm{b}}$ \\
Hip width, m & $0.534^{\mathrm{a}}$ & $0.573^{\mathrm{b}}$ & $0.597^{\mathrm{c}}$ \\
Withers height, m & $1.45^{\mathrm{a}}$ & $1.50^{\mathrm{ab}}$ & $1.53^{\mathrm{b}}$ \\
Chest depth, m & $0.791^{\mathrm{a}}$ & $0.830^{\mathrm{ab}}$ & $0.859^{\mathrm{b}}$ \\
Heart girth, m & $2.07^{\mathrm{a}}$ & $2.13^{\mathrm{ab}}$ & $2.21^{\mathrm{b}}$ \\
Diagonal length, m & $1.59^{\mathrm{a}}$ & $1.68^{\mathrm{ab}}$ & $1.76^{\mathrm{b}}$ \\
BCS & 1.90 & 1.82 & 2.06 \\
BW, kg & $547^{\mathrm{a}}$ & $640^{\mathrm{ab}}$ & $700^{\mathrm{b}}$ \\
\hline
\end{tabular}

${ }^{\mathrm{a}-\mathrm{c}}$ Different letters indicate significant differences at $P<0.05$.

${ }^{1} \mathrm{BCS}$ ranges from 0 to 5 (Bazin et al., 1984).

\section{BW Estimation Using 3D Morphological Traits}

When we attempted to predict BW using only partial volume, the model had an RMSE of $25.4 \mathrm{~kg}$ and an $\mathrm{R}^{2}$ of 0.92 (Table 6 , equation [5]). The addition to this model of an individual effect on the slope and intercept increased the $\mathrm{R}^{2}$ to 0.98 and decreased the RMSE to $14.3 \mathrm{~kg}$ (Table 5, equation [7]). The coefficients of the individual slopes of equation [7] (Table 5) varied from 0.44 to $0.93 \mathrm{~kg} / \mathrm{L}$; without individual effects on the slope and intercept, the slope was $0.98 \mathrm{~kg} / \mathrm{L}$ (Figure 5).

When partial surface area, HW, HG, CD, DL, and BCS were included in the model, BW could be predicted with an RMSE of $22.1 \mathrm{~kg}$ and an $\mathrm{R}^{2}$ of 0.94 (Table 5 , equation [6]). The addition of individual slopes and intercepts to the model increased the $\mathrm{R}^{2}$ to 0.98 , and decreased the RMSE to $12.1 \mathrm{~kg}$ (Table 5, equation [8]; Table 7).

\section{Density and Investigation of Differences Among Individuals}

The individual slopes observed in the prediction of BW with partial volume only were found to be linked
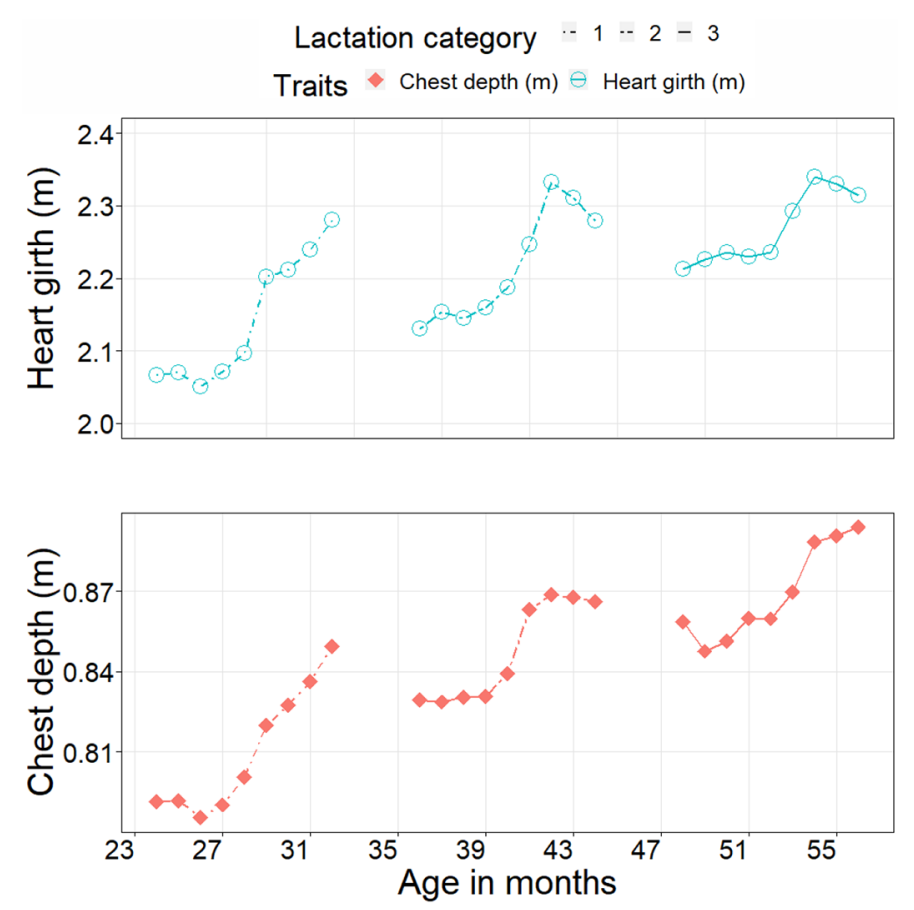

Figure 3. Heart girth (m) and chest depth (m) according to average age, presented by parity $(n=8$ primiparous, 4 in their second lactation, and 4 in their third lactation or higher).

to the average change in body density observed during the study $(\mathrm{r}=0.6, P<0.01)$. This change in body density over the course of lactation was explained by the change in $\mathrm{BCS}$, the change in $\mathrm{CD}$, and the change in DL $\left(\mathrm{R}^{2}=0.28 ; P\right.$-value $<0.05$; Table 7$)$. When the individual slopes in equation [7] (Table 5) were replaced with these 3 variables, the $R^{2}$ value reached 0.94 and the RMSE was $22.8 \mathrm{~kg}$ (Table 7 ), which was 0.02 points higher and $2.6 \mathrm{~kg}$ lower, respectively, than the values obtained when BW was predicted by partial volume only (Table 5, equation [5]). When morphological traits and BCS were added to this model, the prediction of

Table 4. Changes in selected morphological traits during each lactation (from mo 1-9 of lactation) and a comparison of these changes between lactations (contrast method) ${ }^{1}$

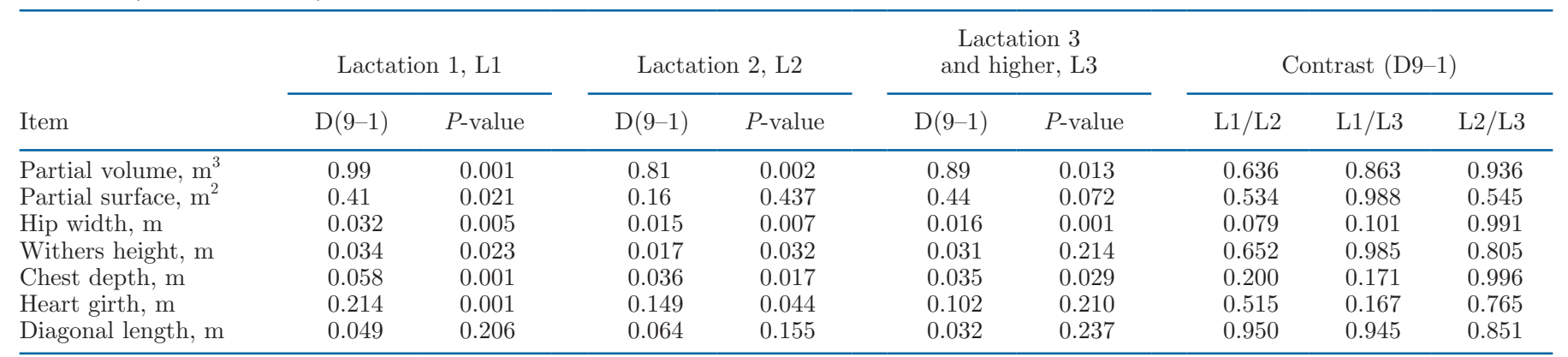

${ }^{1} \mathrm{D}(9-1)=$ difference in absolute value between mo 9 and mo 1 of lactation. Contrast (D9-1) = comparison of (D9-1) values between lactations, using contrast test (Tukey). 


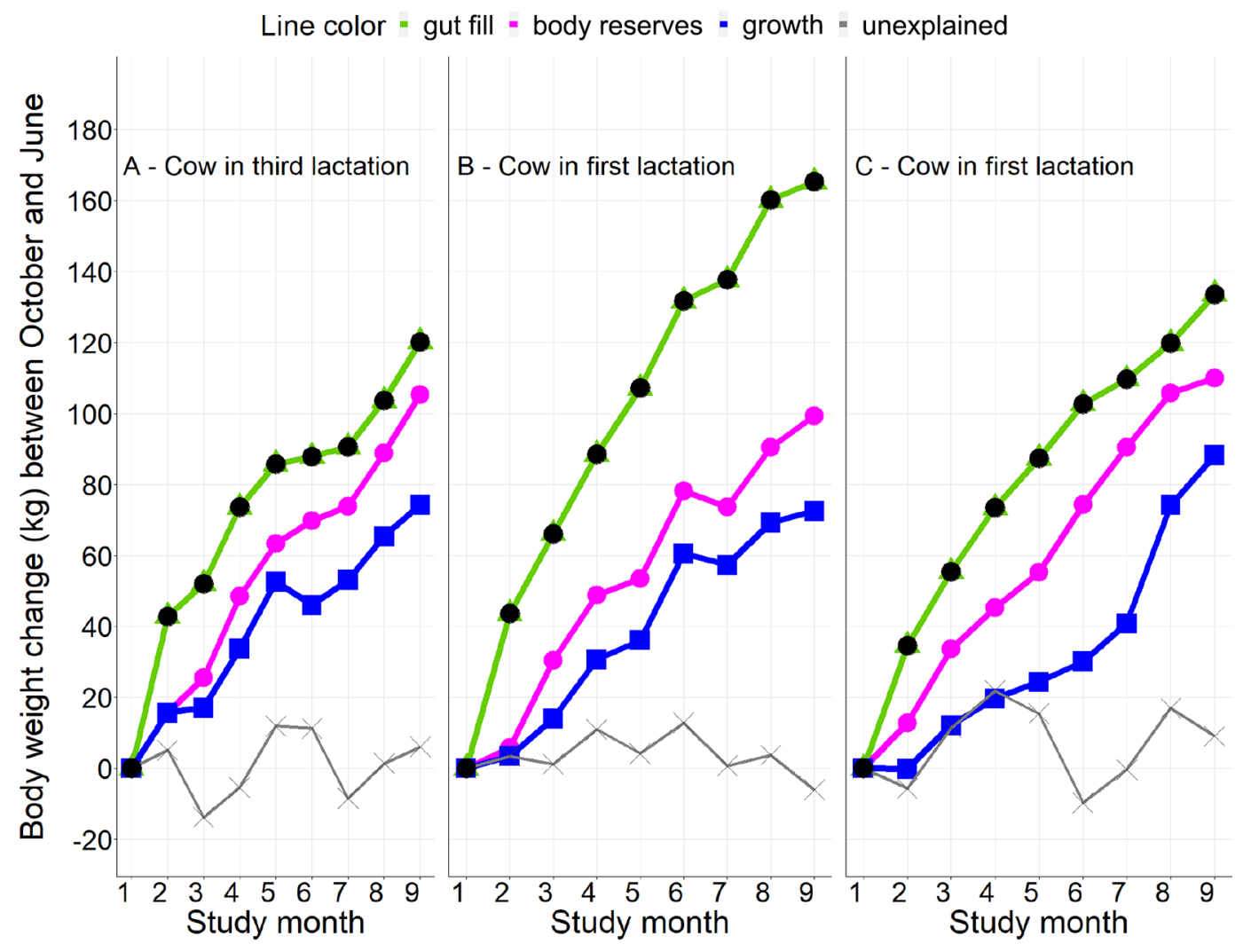

Figure 4. Overall change during lactation in BW, decomposed into its 3 component factors - growth (blue), body reserves (pink), and gut fill (green) - together with the unexplained (i.e., residual error of the model; gray), in 3 different cows (A, B, and C).

BW improved to reach an $\mathrm{R}^{2}$ of 0.96 and an RMSE of $17.9 \mathrm{~kg}$ (Table 7$)$.

\section{DISCUSSION}

Based on our results, it is clear that the relationship between 3D predictors and BW varies among cows. Here, an equation that was based on individual slopes specific to individual cows ([7], see Table 2) was better able to predict $\mathrm{BW}$ than the equivalent equation lacking this information ([5], see Table 2). However, this means that equation [7] cannot be directly applied to other cows or other farms. Furthermore, such individual slopes can only be estimated by regression between BW

Table 5. Adjusted mean of the change in each component of BW $(\mathrm{kg})$ between the first and the last month of study, with one-way ANOVA between primiparous and multiparous cows (mixed model)

\begin{tabular}{lccc}
\hline Item & Primiparous & Multiparous & $P$-value \\
\hline Gut fill & 22.4 & 3.2 & 0.09 \\
Growth & 56.5 & 50.3 & 0.63 \\
Body reserves & 8.2 & 13.3 & 0.41 \\
Residual error & 1.6 & 4.8 & - \\
\hline
\end{tabular}

and partial volume using data on the cows of interest, making true prediction quite impossible. Therefore, the objective in the future will be to better understand the meaning of the individual slopes observed in this model to replace them with biological variables (e.g., BCS changes). Indeed, if we are able to explain the origin of these individual slopes using biological variables, then we should be able to obtain similar prediction results as with equation [7] but without the random slopes and intercept.

\section{Holstein Cows Keep Growing, Even in Their Third or Higher Lactations}

The continuous increase we observed in almost all morphological traits indicated that all cows grew in size, including those in L3. As expected, though, primiparous cows grew more than their multiparous counterparts, especially with respect to $\mathrm{HW}$ and $\mathrm{CD}$ $(P<0.05)$. Our findings are similar to those reported by Cutullic and Flury (2011) for Holstein, Swiss Fleckvieh, and Simmental cows. The fact that cows continued to grow after L1, and into L2 or L3, suggested that even in these advanced stages, the resource require- 
Table 6. Equations for estimating BW based on 3-dimensional morphological traits using simple regression or a mixed model with a random effect of cows on slopes and intercept (general coefficient \pm SD of random coefficient) ${ }^{1}$

\begin{tabular}{|c|c|c|c|}
\hline Model type & Equation & $\mathrm{R}^{2}$ & $\begin{array}{c}\mathrm{RMSE} \\
(\mathrm{kg})\end{array}$ \\
\hline Simple regression & $\begin{array}{l}{[5] \mathrm{BW}=4.08+0.98 \times \mathrm{PV}} \\
{[6] \mathrm{BW}=71.97+1.11 \times \mathrm{PV}-44.74 \times \mathrm{PS}+353.68 \times \mathrm{HW}+315.41 \times \mathrm{CD}-0.11 \times \mathrm{DL}-} \\
90.99 \times \mathrm{HG}\end{array}$ & $\begin{array}{l}0.92 \\
0.94\end{array}$ & $\begin{array}{l}25.4 \\
22.1\end{array}$ \\
\hline Mixed model & $\begin{array}{l}{[7] \mathrm{BW}=180.56( \pm 120.56)+0.71( \pm 0.17) \times \mathrm{PV}} \\
{[8] \mathrm{BW}=-216.90( \pm 170.44)+0.46( \pm 0.12) \times \mathrm{PV}+717.01( \pm 0.02) \times \mathrm{HW}+70.26( \pm 41.30)} \\
\times \mathrm{HG}\end{array}$ & $\begin{array}{l}0.98 \\
0.98\end{array}$ & $\begin{array}{l}14.3 \\
12.1\end{array}$ \\
\hline
\end{tabular}

${ }^{1} \mathrm{PV}=$ partial volume; $\mathrm{PS}=$ partial surface; HW = hip width; $\mathrm{CD}=$ chest depth; $\mathrm{DL}=$ diagonal length; HG $=$ heart girth; $\mathrm{RMSE}=$ root mean square error.

ments for growth were not negligible. Currently, most feeding systems assume that cows finish growing by the end of their first lactation, at which point they cease to require any appreciable energy for growth. For example, the French feeding system accounts for growth requirements until cows are $40 \mathrm{mo}$ old (Faverdin et al., 2010), and the National Research Council (2001) considers that the requirement for growth disappears after first calving. However, our results suggested that, by not dedicating resources to growth for cows after their first calving and during their subsequent lactations, such feeding systems may not adequately meet the requirements of these growing cows. Furthermore, this growth requirement may vary considerably among individual cows, as demonstrated by our decomposition analysis of BW gain into its components (growth, body reserves, and gut fill). Here, the growth component varied from $21.8 \%$ to $105.3 \%$ of BW gain, whereas body reserves varied between $-3.8 \%$ and $44.8 \%$ of BW gain. These results revealed losses in body reserves and a negative value for the residual error of the model, which ultimately meant that, in some cases, growth gain was greater than the live weight gain over the study period. This among-cow variability in the composition of BW gain was also evident in the fact that BW prediction was improved in the model that used partial volume together with individual slopes and intercepts, which represented differences in body density among cows. Taken together, our results highlighted that BW gain could not be homogeneously decomposed into growth, body reserves, and gut fill in any uniform manner across cows or over time. For a given gain in BW, differences in body composition among individuals (e.g., higher or lower proportion of lipids or proteins) will lead to differences in the energetic cost of this gain because the cost to gain body lipids is higher than the cost to gain body proteins (Emmans, 1994; Friggens and Ingvartsen, 2002; cited by Friggens et al., 2007). The lack of difference between primiparous and multiparous cows in the decomposition of BW in this study is in opposition with the change in the composition of BW gain with age and subsequent lactations described in the literature (Garrett et al., 1959; Robelin, 1986; Chizzotti et al., 2007; cited in Agabriel et al., 2018). Future studies that follow growth and changes over a longer period of time (from first calving to fourth lactation or higher), instead of the single lactation examined here, will be indispensable to confirm or refine these results. In addition, examination of a larger number of cows would make it possible to better detect different patterns in growth, BW gain, or its component factors, and improve our understanding of the factors that affect the estimation of BW from volume. Overall, our results highlighted the need for further investigation of the change in the composition of BW gain with age, especially for adult dairy cows, so that it can be better accounted for in feeding systems.

Table 7. Equations for estimating the change in density in each month of the study (with respect to the first month) based on BCS and 3-dimensional morphological traits; equations for estimating BW by taking into account density (in interaction with partial volume) ${ }^{1}$

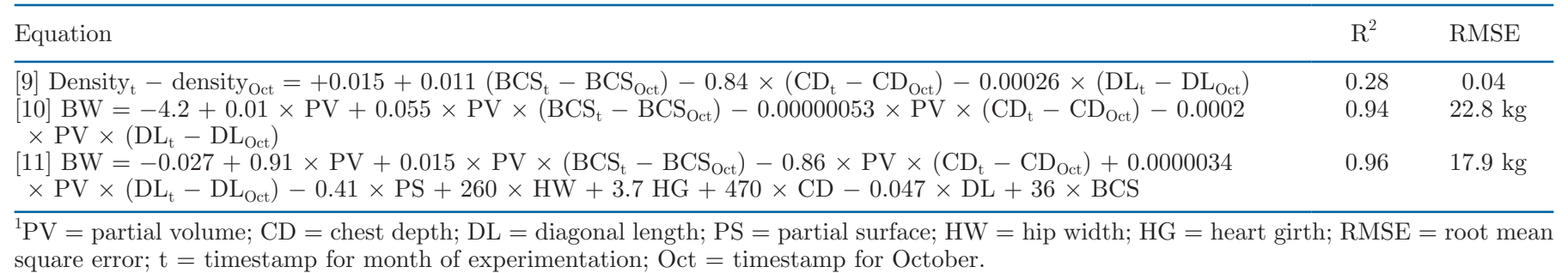




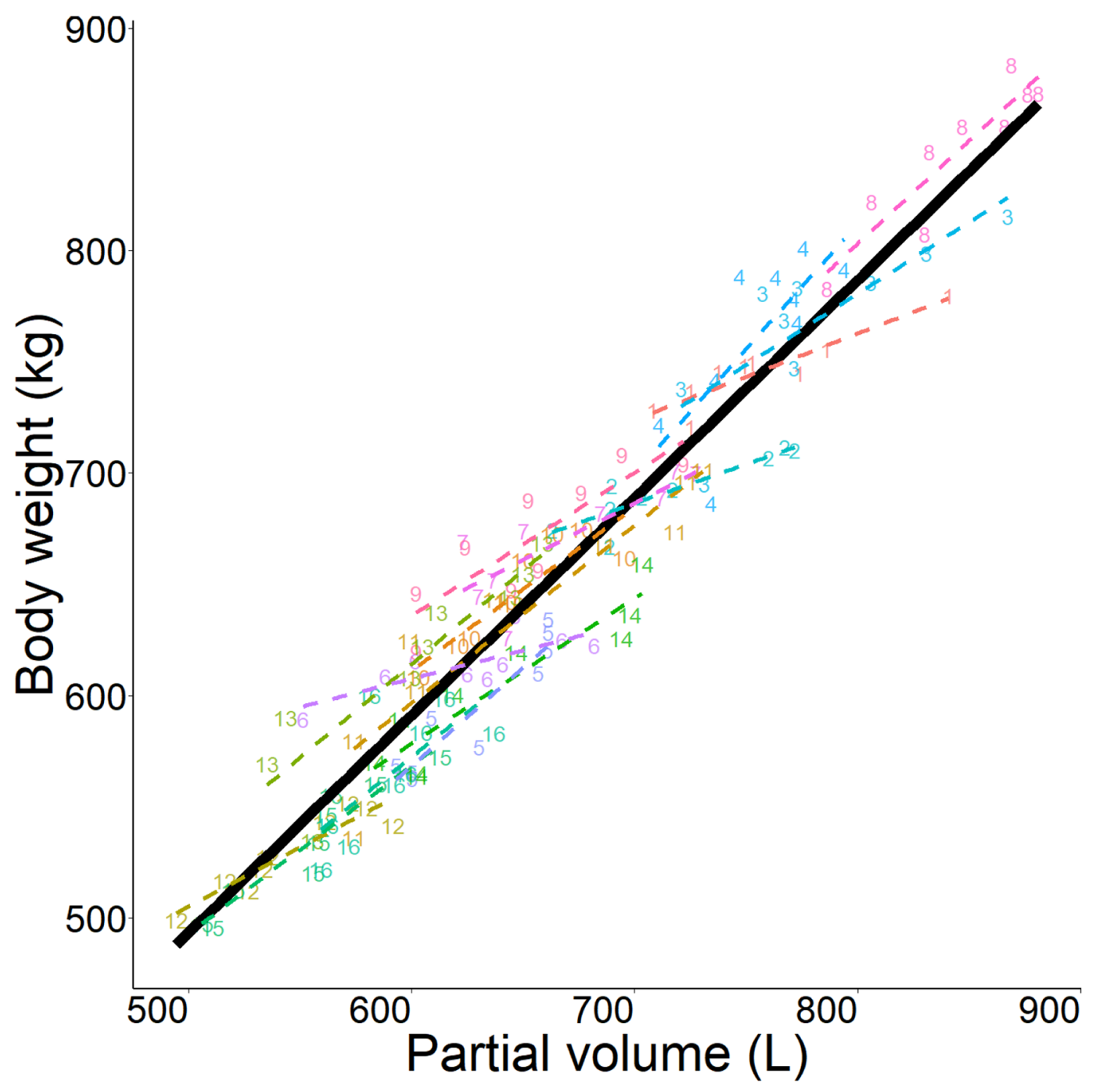

Figure 5. Estimation of BW $(\mathrm{kg})$ based on partial volume $(\mathrm{L})$ using a linear regression or mixed model with animal-specific intercepts and slopes. The linear regression is represented by the black line, and the mixed model regression is represented by the colored lines, each fitted to an individual cow (number and color $=1$ cow, $\mathrm{n}=16$ Holstein cows).

\section{Partial Volume Is a Relevant Indicator of BW}

Until recently, volume had seldom been used to estimate BW. The work of Martins et al. (2020) represented a step forward in this regard, with equations developed to estimate volume from lateral images of cows. As far as we know, our work represented the first effort to calculate volume from a complete 3D image of an animal. Here, we found that BW could be estimated by partial volume with an error of $25.4 \mathrm{~kg}$, which was close to that obtained in a previous study by our group $(24.9 \mathrm{~kg}$; Le Cozler et al., 2019b). For the most part, this degree of error is smaller than that obtained by other approaches that were based on 3D images and included several variables as follows: $42.0 \mathrm{~kg}$ in the study of Miller et al. (2019), $41.2 \mathrm{~kg}$ for Song et al. (2018), $42.7 \mathrm{~kg}$ for Kuzuhara et al. (2015), and $19.2 \mathrm{~kg}$ for Gomes et al. (2016). Martins et al. (2020) obtained a prediction error for BW of $49.2 \mathrm{~kg}$ based on lateral images, but this was reduced to $26.9 \mathrm{~kg}$ when they switched to dorsal images. The lowest degree of error in this group, which was reported by Gomes et al. (2016), was obtained using lighter animals; $19.2 \mathrm{~kg}$ represents a coefficient of variation of $3 \%$, which is equivalent to the $3.9 \%$ we obtained here using equation [5]. The improved results of Gomes et al. (2016) can also be explained by their use of synthetic variables, whereas the other studies were based on linear variables. Therefore, future efforts should consider estimating BW from 3D images using a larger number of synthetic variables, or even with 
methods based on artificial intelligence, which do not require the identification and estimation of specific traits for prediction.

As discussed above, we obtained the smallest degree of error when we included individual slopes in the model estimating BW based on partial volume, highlighting the importance of interindividual variability. Part of this variability may have originated from differences in body density, which had an important effect on the relationship between BW and volume. Indeed, using 3D imaging, Lebreton et al. (2020) demonstrated that a gain of $10 \mathrm{~kg}$ of $\mathrm{BW}$ does not translate into a change in abdominal volume (including rumen) of $10 \mathrm{~L}$, and vice versa. They reported regression coefficients ranging from 0.4 to 0.7 , and by taking into account these individual differences, they obtained a predictive model with an error close to $12 \mathrm{~kg}$. Unfortunately, calculating and accounting for individual slopes is not possible in routine prediction. However, the $25 \mathrm{~kg}$ error we obtained in our models without individual slopes can be considered a good start that can be further improved with better knowledge of animal density, for example through 3D imaging that precisely and continuously records BCS (Fischer et al., 2015) or feed intake (Shelley et al., 2016).

\section{CONCLUSIONS}

Using 3D images of the entire body of dairy cows, we demonstrated here that dairy cows keep growing for longer than previously believed, well into their second or higher lactation. As expected, the primiparous cows in this study grew more than their multiparous counterparts. Growth was the most important component of BW gain, accounting for about $64 \%$ of the total, with the remaining contributions coming from increases in gut fill and body reserves. This study also confirmed that it is possible to estimate BW from volume, with an error of $25.4 \mathrm{~kg}$. The precision of prediction was further improved by adding individual slopes and intercepts in the model, which highlighted the importance of considering interindividual differences in body density (i.e., in body composition) in the prediction of BW. Overall, this study demonstrated the potential of $3 \mathrm{D}$ imaging as a low-cost tool for monitoring animal growth on farms, possibly in different livestock species.

\section{ACKNOWLEDGMENTS}

The authors thank the team of the "Installation Expérimentale en Production de Lait" of the UMR Physiologie, Environnement, Génétique pour l'Animal et les Systèmes d'Elevage (PEGASE) for the excellent care of the animals during the experiment. The authors are grateful to the national projects Morpho3D (Casdar, French Ministry of Agriculture, Paris, France), Deffilait (Agence Nationale de la Recherche, Paris, France, ANR-15-CE20-0014), and APIS-GENE (Paris, France) for funding this research. The authors have not stated any conflicts of interest.

\section{REFERENCES}

Agabriel, J., V. Berthelot, G. Cantalapiedra-Hijar, and D. Sauvant. 2018. Réponse de la croissance aux variations d'apports alimentaires en phase d'élevage ou en finition. INRA. Éditions Quae.

Banos, G., M. P. Coffey, and S. Brotherstone. 2005. Modeling daily energy balance of dairy cows in the first three lactations. J. Dairy Sci. 88:2226-2237. https://doi.org/10.3168/jds.S0022-0302(05)72898 $-8$.

Bazin, S., P. Augeard, M. Carteau, Y. Chilliard, G. Cuylle, C. Disenhaus, G. Durand, R. Espinasse, A. Gascoin, M. Godineau, D. Jouanne, O. Ollivier, and B. Remond. 1984. Scoring grid for the fattening condition of Black Pie cows. Institut technique de l'élevage bovin.

Chilliard, Y., B. Rémond, J. Agabriel, J. Robelin, and R. Vérité. 1987. Variations in digestive content and body reserves during the gestation-lactation cycle. Bull Tech CRZV Theix, INRA 70:117-132.

Chizzotti, M. L., S. C. Valaderes Filho, L. O. Tedeschi, F. H. M. Chizzotti, and G. E. Carstens. 2007. Energy and protein requirements for growth and maintenance of F1 Nellore $\times$ Red Angus bulls, steers and heifers. J. Anim. Sci. 85:1971-1981. https://doi.org/10 $.2527 /$ jas.2006-632.

Cutullic, E., and C. Flury. 2011. Dairy efficiency: Consideration of live weight estimated by linear description in the breeding values of 3 Swiss dairy breeds. Haute école spécialisée bernoise and Haute école suisse d'agronomie HESA.

Emmans, G. C. 1994. Effective energy: A concept of energy utilization applied across species. Br. J. Nutr. 71:801-821. https://doi.org/10 $.1079 /$ BJN19940188.

Faverdin, P., A. Charrier, and A. Fischer. 2017. Prediction of dry matter intake of lactating dairy cows with daily live weight and milk production measurements. Pages 35-44 in Proceedings of the 8th European Conference on Precision Livestock Farming (ECPLF).

Faverdin, P., R. Delagarde, L. Delaby, and F. Meschy. 2010. Dairy cow feeding. Pages 23-58 in Alimentation des bovins, ovins, caprins. Besoins des animaux - Valeurs des aliments - Table Inra 2007, mise à jour 2010, éditions.

Fischer, A., T. Luginbühl, L. Delattre, J. M. Delouard, and P. Faverdin. 2015. Rear shape in 3 dimensions summarized by principal component analysis is a good predictor of body condition score in Holstein dairy cows. J. Dairy Sci. 98:4465-4476. https://doi.org/ 10.3168/jds.2014-8969.

Fox, J., and S. Weisberg. 2011. An $\{\mathrm{R}\}$ Companion to Applied Regression. Sage Publications Inc.

Friggens, N. C., and K. L. Ingvartsen. 2002. The importance of mobilisation and deposition of body reserves for calculation of energy requirements. Pages 56-61 in Boologisk Selskabs Seminar. Dansk Boologisk Selskab.

Friggens, N. C., C. Ridder, and P. Løvendahl. 2007. On the use of milk composition measures to predict the energy balance of dairy cows. J. Dairy Sci. 90:5453-5467. https://doi.org/10.3168/jds.2006-821.

Friggens, N. C., V. M. Thorup, and D. Edwards. 2011. On-farm estimation of energy balance of dairy cows using frequent live weight and body condition score measurements. Renc. Rech. Rumin. en France 18:39-42.

Garrett, W. N., J. H. Meyer, and G. P. Lofgreen. 1959. The comparative energy requirements of sheep and cattle for maintenance and gain. J. Anim. Sci. 18:528-547. https://doi.org/10.2527/jas1959 $.182528 \mathrm{x}$.

Gomes, R. A., G. R. Monteiro, G. J. F. Assis, K. C. Busato, M. M. Ladeira, and M. L. Chizzotti. 2016. Technical note: Estimating body weight and body composition of beef cattle trough digital im- 
age analysis. J. Anim. Sci. 94:5414-5422. https://doi.org/10.2527/ jas.2016-0797.

Heinrichs, A. J., G. W. Rogers, and J. B. Cooper. 1992. Predicting body weight and wither height in Holstein heifers using body measurements. J. Dairy Sci. 75:3576-3581. https://doi.org/10.3168/ jds.S0022-0302(92)78134-X.

Kazhdan, M., and H. Hoppe. 2013. Screened Poisson surface reconstruction. ACM Trans. Graph. 32:29. https://doi.org/10.1145/ 2487228.2487237.

Kuzuhara, Y., K. Kawamura, R. Yoshitoshi, T. Tamaki, S. Sugai, M. Ikegami, Y. Kurokawa, T. Obitsu, M. Okita, T. Sugino, and T. Yasuda. 2015. A preliminarily study for predicting body weight and milk properties in lactating Holstein cows using a three-dimensional camera system. Comput. Electron. Agric. 111:186-193. https://doi.org/10.1016/j.compag.2014.12.020.

Le Cozler, Y., C. Allain, A. Caillot, J. M. Delouard, L. Delattre, T. Luginbuhl, and P. Faverdin. 2019a. High-precision scanning system for complete 3D cow body shape imaging and analysis of morphological traits. Comput. Electron. Agric. 157:447-453. https: //doi.org/10.1016/j.compag.2019.01.019.

Le Cozler, Y., C. Allain, C. Xavier, L. Depuille, A. Caillot, J. M. Delouard, L. Delattre, T. Luginbuhl, and P. Faverdin. 2019b. Volume and surface area of Holstein dairy cows calculated from complete 3D shapes acquired using a high-precision scanning system: Interest for body weight estimation. Comput. Electron. Agric. 165:104977. https://doi.org/10.1016/j.compag.2019.104977.

Le Cozler, Y., O. Recoursé, E. Ganche, D. Giraud, J. Danel, M. Bertin, and P. Brunschwig. 2012. A survey on dairy heifer farm management practices in a Western-European plainland, the French Pays de la Loire region. J. Agric. Sci. 150:518-533. https://doi.org/10 $.1017 /$ S0021859612000032.

Lebreton, A., Y. Le Cozler, M. Guilloux, and P. Faverdin. 2020. Estimating variations of ruminal content using $3 \mathrm{D}$ images of the abdomen. Renc. Rech. Rumin. en France 25:60 (in French).

Lenth, R. V. 2016. Least-squares means: The R package lsmeans. J. Stat. Softw. 69:1-33. https://doi.org/10.18637/jss.v069.i01.

Maltz, E. 1997. The body weight of the dairy cow: III. Use for online management of individual cows. Livest. Prod. Sci. 48:187-200. https://doi.org/10.1016/S0301-6226(97)00026-2.

Martins, B. M., A. L. C. Mendes, L. F. Silva, T. R. Moreira, J. H. C. Costa, P. P. Rotta, M. L. Chizzotti, and M. I. Marcondes. 2020. Estimating body weight, body condition score, and type traits in dairy cows using three dimensional cameras and manual body measurements. Livest. Sci. 236:104054. https://doi.org/10.1016/j .livsci.2020.104054.
Miller, G. A., J. J. Hyslop, D. Barclay, A. Edwards, W. Thomson, and C. A. Duthie. 2019. Using 3D imaging and machine learning to predict liveweight and carcass characteristics of live finishing beef cattle. Front. Sustain. Food Syst. 3:30. https://doi.org/10.3389/ fsufs.2019.00030.

National Research Council. 2001. Nutrient Requirements of Dairy Cattle. 7th rev. ed. National Academy Press.

Pinheiro, J., D. Bates, S. DebRoy, D. Sarkar, and R Core Team. 2018. \{nlme\}: Linear and nonlinear mixed effects models - R package version 3.1-137. Accessed Feb. 16, 2022. https://cran.r-project.org/ web/packages/nlme/index.html.

Rémond, B., H. Brugère, C. Poncet, and R. Baumont. 1995. The content of the reticulo-rumen. Pages 263-298 in Nutrition des Ruminants Domestiques, INRA Editions.

Robelin, J. 1986. Bases physiologiques de la production de viande: Croissance et développement des bovins. D. Micol, ed. INRA.

Roche, J. R., N. C. Friggens, J. K. Kay, M. W. Fisher, K. J. Stafford, and D. P. Berry. 2009. Invited review: Body condition score and its association with dairy cow productivity, health, and welfare. J. Dairy Sci. 92:5769-5801. https://doi.org/10.3168/jds.2009-2431.

Shelley, A. N., D. L. Lau, A. E. Stone, and J. M. Bewley. 2016. Short communication: Measuring feed volume and weight by machine vision. J. Dairy Sci. 99:386-391. https://doi.org/10.3168/jds.2014 $-8964$.

Song, X., E. A. M. Bokkers, P. P. J. van der Tol, P. W. G. Groot Koerkamp, and S. van Mourik. 2018. Automated body weight prediction of dairy cows using 3-dimensional vision. J. Dairy Sci. 101:4448-4459. https://doi.org/10.3168/jds.2017-13094.

Thorup, V. M., D. Edwards, and N. C. Friggens. 2012. On-farm estimation of energy balance in dairy cows using only frequent body weight measurements and body condition score. J. Dairy Sci 95:1784-1793. https://doi.org/10.3168/jds.2011-4631.

\section{ORCIDS}

Y. Le Cozler ๑ https://orcid.org/0000-0001-9644-317X

L. Depuille @ https://orcid.org/0000-0002-3069-3384

A. Lebreton (1) https://orcid.org/0000-0003-2718-3292

L. Delattre $\odot$ https://orcid.org/0000-0001-5720-3982

T. Luginbuhl $\odot$ https://orcid.org/0000-0002-9622-920X

P. Faverdin (๑ https://orcid.org/0000-0003-3883-8389 